\title{
Quantifying the decline of the Martial Eagle Polemaetus bellicosus in South Africa
}

\author{
ARJUN AMAR and DANIËL CLOETE
}

\section{Summary}

Human populations in Africa are growing at a faster rate than in any other region; this growth will exert increasing pressures on the continent's wildlife resources and declines in wildlife are already being observed. Species occupying higher trophic levels may be amongst the most useful indicators of this pressure and raptorial birds have already proven to be particularly useful in highlighting problems with their environment. The Martial Eagle is an African endemic which is thought to be declining and was recently uplisted to globally Vulnerable, although data on population trends are almost entirely lacking. The Southern African Bird Atlas Project (SABAP) I and 2 are citizen science projects that represent a rare opportunity, within an African context, to quantify population changes over a 20-year period. We use data from these surveys to explore changes in reporting rates for this species in South Africa between SABAP 1 (1987-1992) and SABAP 2 (2007-2012) at the scale of quarter-degree grid cells. Previous research suggests that such comparisons accurately reflect changes in breeding numbers for this species. We found an overall decline in reporting rates of c.6o\%, with more cells showing loss or declines $(75 \%)$ than those showing colonisation or increases $(25 \%)$. No differences in reporting rate change were found between provinces, suggesting a relative uniform decline across the country. There were, however, differences between biomes with declines recorded in all biomes apart from Albany Thicket, Succulent Karoo and Fynbos (south-western biomes). Declines differed inside and outside protected areas, with larger declines outside $(64 \%)$ than inside $(42 \%)$ protected areas, although even within large protected areas significant declines were observed. These results support the uplisting of the species' conservation status and suggest that even within protected areas the species is not immune to the drivers of decline.

\section{Introduction}

Human population growth rates in Africa are among the highest in the world (Haub and Kent 1989). This population growth is putting unprecedented pressure on the natural environment; amongst those pressures are the intensification and expansion of farming, increased development and an increase in the legal and illegal trade of dead and live wild animals (Balmford et al. 2001, Brashares and Sam 2005). The impacts of these increased pressures are beginning to be detected in wild animal populations and declines in a variety of taxa have been reported, with species belonging to higher trophic guilds being particularly at risk (Thiollay 2006, Henschel et al. 2014, Bauer et al. 2015, Ogada et al. 2015). Protected areas have become vital for the preservation of biodiversity in Africa (Bauer et al. 2015), but even in these areas, species are not always immune to anthropogenic impacts (Woodroffe and Ginsberg 1998, Herremans and Herremans-tonnoeyr 2000, Western et al. 2009). In order to mitigate the negative impacts of these pressures on wild animal species it is important to understand the patterns of these declines, which can help identify the factors driving population change (Amar et al. 2011). 
Comprehensive monitoring programmes, involving systematic repeat surveys over time, have played a crucial role in documenting and elucidating the cause of national biodiversity declines in many developed countries (Buckland et al. 2005, Hewson et al. 2007, Bled et al. 2013). Such monitoring schemes have often been supported by governments or large NGOs. However, within Africa these types of monitoring programmes are generally non-existent. The few re-surveys which have occurred are generally small scale (i.e. covering specific protected areas (Lindsell et al. 2016)) or have involved repeats of historic road transects (Thiollay 2006, Virani et al. 2011). One exception to this situation in Africa is the Southern African Bird Atlas Project (SABAP); these national surveys were carried out in several Southern African countries over a 5-year period (1987-1992), and within South Africa have been repeated, recommencing in 2007 and are still on-going. These surveys therefore present a unique opportunity to examine changes in bird populations in South Africa over a period of time where there has been considerable development (Odhiambo 2009).

Birds of prey are known to be particularly vulnerable to environmental change and may therefore act as good indicators of changes in environmental quality (Sergio et al. 2006). Only a few re-surveys of raptor populations have occurred in Africa over a sufficiently long temporal scale, but these have documented large declines for many species with particularly large declines recorded for large eagles and vultures (Thiollay 2006, Virani et al. 2011). These species may be particularly vulnerable to changes in habitat quality or direct persecution because of their slow reproductive rate and particularly their low mortality rates (Ortega et al. 2009, Murgatroyd et al. 2016). For example, Virani et al. (2011) found declines of many large raptors from repeat road survey carried out in southern Kenya. Similarly, Thiollay (2006), found large declines in raptor communities in West Africa from road surveys between the 1980s and 200os, particularly for vultures and large eagles. One of these species, the Martial Eagle Polemaetus bellicosus declined to almost extinction outside of protected areas and in many areas of Africa the species is now heavily reliant on these protected areas for its continued existence (Herremans and Herremanstonnoeyr 2000, Thiollay 2006).

The Martial Eagle is the largest eagle species in Africa, where it is widely distributed throughout sub-Saharan Africa (BirdLife International 2016). The species is considered to be declining throughout much of its range (Brown 1991, Thiollay 2006) and as a result the species has recently been uplisted to 'Vulnerable' by IUCN (BirdLife International 2016). Within South Africa the species has recently been uplisted to regionally 'Endangered', due to suspected population declines (Underhill 2012, Taylor et al. 2015). Various causes for declines have been proposed and appear to vary from region to region. Within West Africa, Thiollay (2006) attributed these declines to loss of prey species, particularly large birds and medium sized mammals, which have declined to near extinction outside of protected areas. In contrast, Brown (1991) attributed declines in his region of Namibia to persecution by livestock farmers.

In this paper, we take advantage of the unique data provided through SABAP to explore whether there have been declines of Martial Eagles in South Africa over a two-decade period using reporting rates from SABAP I (1987-1992) and SABAP 2 (2007-2012). Furthermore, in the hope of better understanding the processes that may be driving population changes, we examine whether changes have occurred equally between provincial regions, between habitat types and inside and outside of protected areas.

\section{Methods}

\section{Martial Eagle survey data}

We used data on Martial Eagle occurrence from the first and second Southern African Bird Atlas Project (SABAP 1, 1987-1992; Harrison and Underhill 1997; and SABAP 2, 1997-ongoing; http://sabap2.adu.org.za/). SABAP is a citizen science survey, based on checklists (cards), which record the species of birds seen in a given area for a given period of time. In SABAP 2 improvements 
were made to the SABAP I protocol. Spatially, SABAP I was implemented at quarter-degree grid cell (QDGC) resolution which, in South Africa, translates to an area c. $26 \mathrm{~km} \times 27 \mathrm{~km}$. SABAP 2 is spatially more refined, being surveyed at the pentad scale ( 9 pentads in one QDGC; $c .9 \mathrm{~km} \times 9 \mathrm{~km}$ each). Temporally, SABAP I used checklists that could be carried out over a maximum period of one month, whereas for SABAP 2 surveys cover a maximum period of five days (Bonnevie 2011). These spatial and temporal differences introduce several difficulties, which are not insurmountable, in comparing SABAP I with SABAP 2 (see Bonnevie 2011, Bled et al. 2013 for more details). Although the protocols for data collection differ between the two survey periods, SABAP 2 was designed to allow comparison with SABAP 1 and to examine changes in reporting rates as a means to investigate population changes across the range (ADU 2013). To match the two surveys spatially, the SABAP 2 pentad data were combined for each QDGC. Most importantly, for our study species, a study validating the use of $\mathrm{SABAP}_{1}$ and 2 comparisons has been undertaken; Amar et al. (2016) found similar estimates of population change comparing SABAP surveys with independent field nest surveys. This suggests that, despite discrepancies between SABAP 1 and SABAP 2 protocols, SABAP comparisons do enable the documentation of population changes in an accurate manner (Hofmeyr 2012, Shaw 2013).

SABAP $_{1}$ data were collected between 1987 and 1992. SABAP 2 data collection began in 2007 and we used SABAP 2 data from July 2007 to August 2012. For each QDGC, we used data on the total number of cards and the number of cards recording Martial Eagles ('positive cards') to calculate a reporting rate for each cell in each period (number of positive cards / total cards). We assumed no false positives, i.e. that the species was always correctly identified. This was a reasonable assumption, as the species is large and highly distinctive. For the analyses, we only used QDGCs which had at least five completed cards in both SABAP periods.

\section{Environmental and geographical data - classification of each QDGC}

We extracted geographical data which was applicable to each QDGC. To achieve this, relevant data sources were extracted using ArcGIS 9.3 (ESRI 2011). The QDGC grid was re-projected to Albers Equal Area to minimise distortion. Data were extracted only for grid cells clipped to the South African geopolitical boundary and, as such, cells that border the coast or neighbouring countries would only be partial cells. The area for each QDGC (and used to extract covariates) was tabulated using zonal statistics, setting the processing cell size at $100 \mathrm{~m}$.

\section{Geopolitical boundaries and biomes}

Each QDGC was assigned a provincial category using National and Provincial boundaries obtained from the Municipal Demarcation Board of South Africa (MDB 2013). Where a QDGC was present in more than one Province, the proportion of each Province was calculated, and the Province with the greatest area coverage assigned to the QDGC. Similarly, data on the nine South African biomes (Albany Thicket, Desert, Forest, Fynbos, Grassland, Indian Ocean Coastal Belt, Nama Karoo, Savanna and Succulent Karoo), sourced from Mucina and Rutherford (2006), were assigned to each QDGC. For ease of analysis any biome type that was dominant in less than 1o cells was reclassified to the second most dominant biome in the cell or to the dominant biome in the surrounding cells if there was no other biome in that cell. This approach reclassified all Desert and Forest biome QDGC's.

\section{Protected areas}

Information on the amount of protected land within each QDGC was derived from the following datasets: National Protected Area Expansion Strategy 2002 (updated in June 2006; BGIS 2008); World Database of Protected Areas (www.protectedplanet.org); and the National Biodiversity Assessment (SANBI 2012). These databases therefore included both formal protected areas 
(i.e. statutory protected areas) and informal protected areas (i.e. statutorily non-gazetted private nature reserves, game reserves and game farms). QDGC were then classified as protected if $\geq 50 \%$ of their area was covered by these formal or informal protected areas. Additionally, we also examined changes within three of South Africa's largest National Parks which were known to be important areas for Martial Eagles; these were Kruger National Park, Kalahari National Gemsbok Park and Hluhluwe-iMfolozi. For this we therefore subset the data to include only QDGCs that were located (i.e $>50 \%$ ) within the boundaries of these parks (see Amar et al. 2016 for further details).

\section{Statistical analysis}

Generalised linear models (GLM) were used to quantify changes in reporting rates between the two SABAP projects. QDGCs where Martial Eagles were never reported were excluded from all subsequent analysis. Our analysis aimed to quantify changes in reporting rates at various levels: 1) nationally, 2) within each province, 3) between biomes and 4) within or outside of protected areas.

GLMs were fitted with a binomial error structure and logit link function. Our response variable was the reporting rate of Martial Eagles in each QDGC for each period (SABAP I or SABAP 2), as a two-vector variable consisting of the number of positive cards and the number of negative cards in each QDGC in each period (Amar et al. 2011, Cunningham et al. 2016). In this way, our analysis explicitly accounted for differences in survey effort (i.e. number of cards) between cells and also within cells between survey periods.

The factor of "Period" (SABAP I or SABAP 2) was fitted as a categorical fixed effect in the model, as an explanatory variable, to examine the change nationally, and within three specific national parks (by analysing only the subset of QDGCs located within these parks) (Amar et al. 2016), and as an interaction to examine the change in reporting rate for each of the other variables fitted as a main effect (e.g. province, biome, protected area status), run as separate models for each term. This interaction therefore tested whether the reporting rate change differed between the two survey periods in different provinces, biomes or depending on whether QDGCs were dominated by protected areas. Thus, on the full dataset, we ran a total of four models. The questions the models were addressing and the terms used in the models were as follows: 1 ) national changes: explanatory variable $=$ Period; 2 ) changes between provinces: explanatory variables $=$ Period + Province + Period $^{*}$ Province; 3 ) changes between biomes: explanatory variables $=$ Period + Biome + Period ${ }^{*}$ Biome; 4 ) changes by protected areas status: explanatory variables $=$ Period + PAstatus + Period ${ }^{*}$ PAstatus. Additionally, to explore changes in the three national parks selected, we ran three models which used the structure of model I (above) but only on a subset of data which included the QDGCs located in each park.

The significance (Chi-square test statistic and $P$-values) of the explanatory terms in the models were explored using the 'anova' function applied to the output from the GLMs. Pairwise comparisons were made using the 'lsmeans' package (Lenth and Hervé, 2013), with corresponding t-test statistics and P-values. All analyses were conducted in R (R Core Team, 2015).

\section{Results}

From the 1,245 quarter-degree grid cells (QDGC) considered for this analysis (those containing at least five cards in each SABAP survey), 475 QDGCs (38.2\%) contained no Martial Eagle records during either SABAP survey and were excluded from further analyses. From the remaining 770 QDGCs used in our analysis, the species disappeared (i.e. only recorded in SABAP I surveys) from 381 QDGCs (49.5\%), declined in 198 QDGCs (25.7\%), increased in 113 QDGCs (14.7\%) and colonised (i.e. only recorded in SABAP 2) 78 QDGCs (10.1\%) (Figure 1).

Across South Africa we found a significant decrease in the reporting rates of Martial Eagles between the two SABAP survey periods (mean reporting rates: SABAP 1, 7.3\% (95\% CI: 6.6-8\%; SABAP 2, 

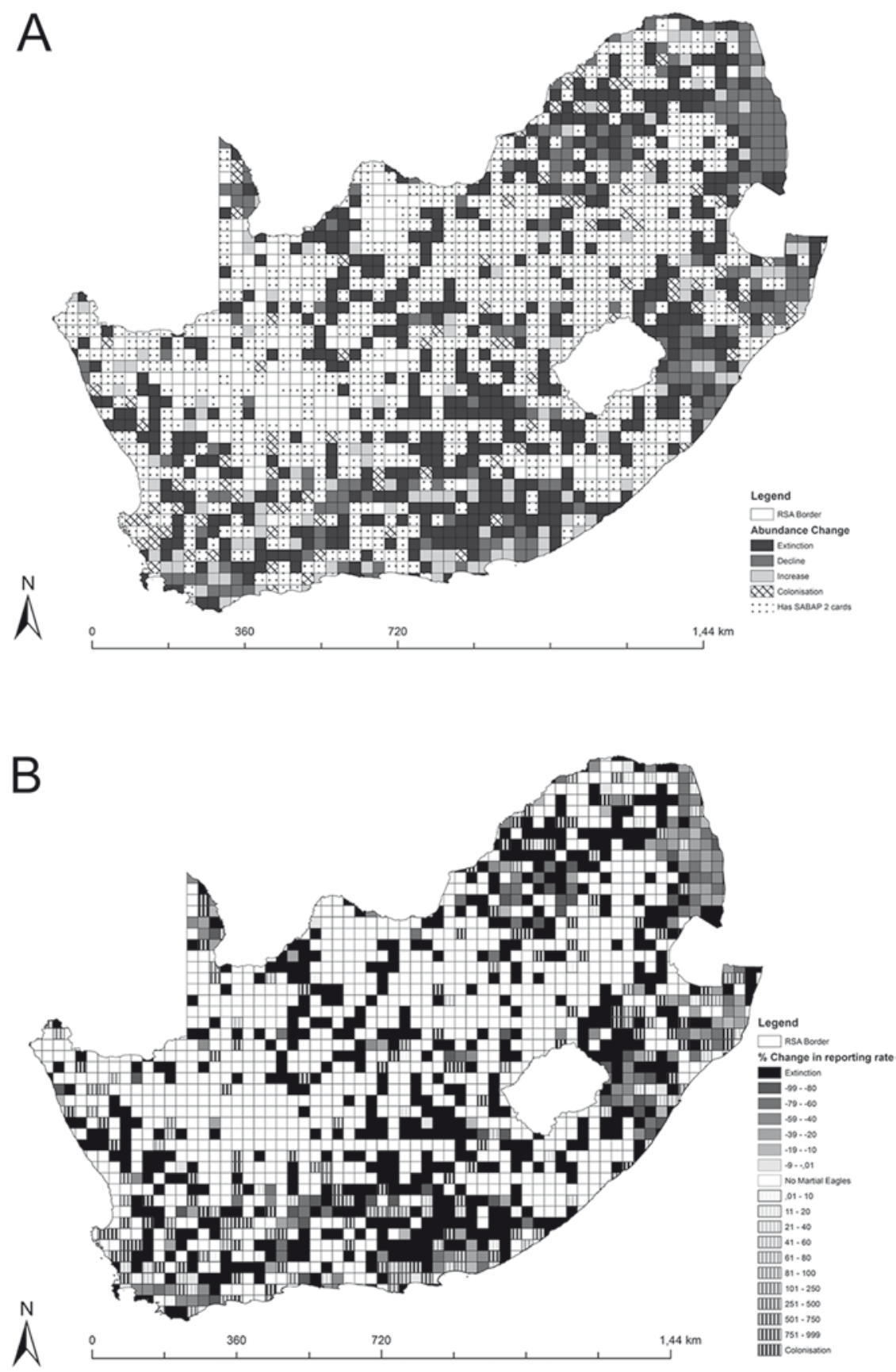

Figure 1. Map showing the Martial Eagle reporting rate changes in South Africa. Map [A] shows changes in four categories (Extinction, Decline, Increase, Colonisation) plus those squares with and without SABAP 2 cards. Map [B] shows the percentage change for each QDGC ranging from decreases being shown through the solid darker colours and increases being shown by the dashed fill. Blank cells are those which had $<5$ cards submitted in either period or where Martial Eagles were not recorded in either survey period. 
$\square$ SABAP1 $\square$ SABAP2

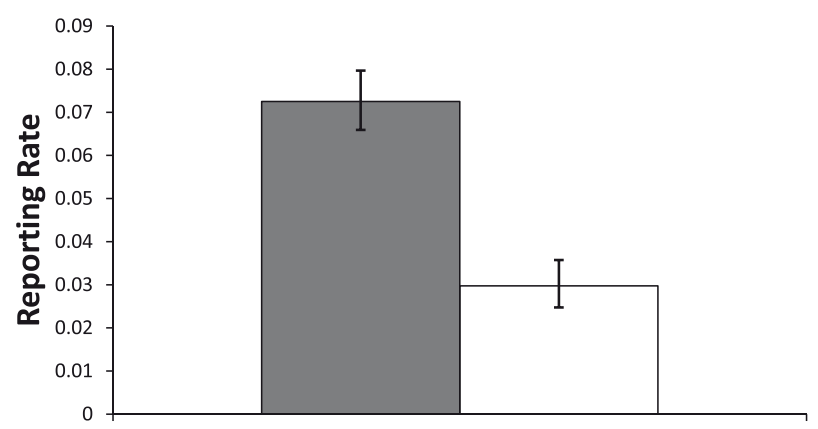

Figure 2. The overall difference in South Africa in the probability of reporting Martial Eagles between SABAP I (1987-1992) and SABAP 2 (2007-2012) (mean $\pm 95 \%$ confidence limit). Data come from the lsmeans output from the general linear model used in the analysis. Differences were highly significant $\left(\chi^{2}=83.7, \mathrm{df}=1, P<0.0001\right)$.

$3.0 \%$ (95\% CI: $2.5-3.6 \%) ; \chi^{2}=83.7, \mathrm{df}=1, P<0.0001$ ). Thus, the reporting rate declined by around $59 \%$ overall across South Africa (Figure 2). No significant interaction between province and survey period was found, indicating that the changes in reporting rates for MEs between the two SABAP surveys were similar between provinces $\left(\chi^{2}=10.1, \mathrm{df}=8, P=0.25\right.$; Figure 3).

Changes in reporting rates differed between biomes, with a significant interaction between biomes and period (Figure $4 ; \chi^{2}=25.2, \mathrm{df}=6, P<0.0001$ ). Pairwise comparisons revealed significant decreases in the Grassland $(-77.9 \%, n=184, t=5.08, P<0.001)$, Indian Ocean Coastal Belt $(-81.5 \%, \mathrm{n}=27, t=3.87, P<0.001)$, Nama Karoo $(-76 \%, n=83, t=4.36, P<0.01)$ and Savanna $(-60.9 \%, n=289, t=9.22, P<0.001$ ) biomes (Figure 4 ). Whereas no significant changes were found in Albany Thicket and Succulent Karoo, and non-significant increases were detected in the Fynbos biome (Figure 4).

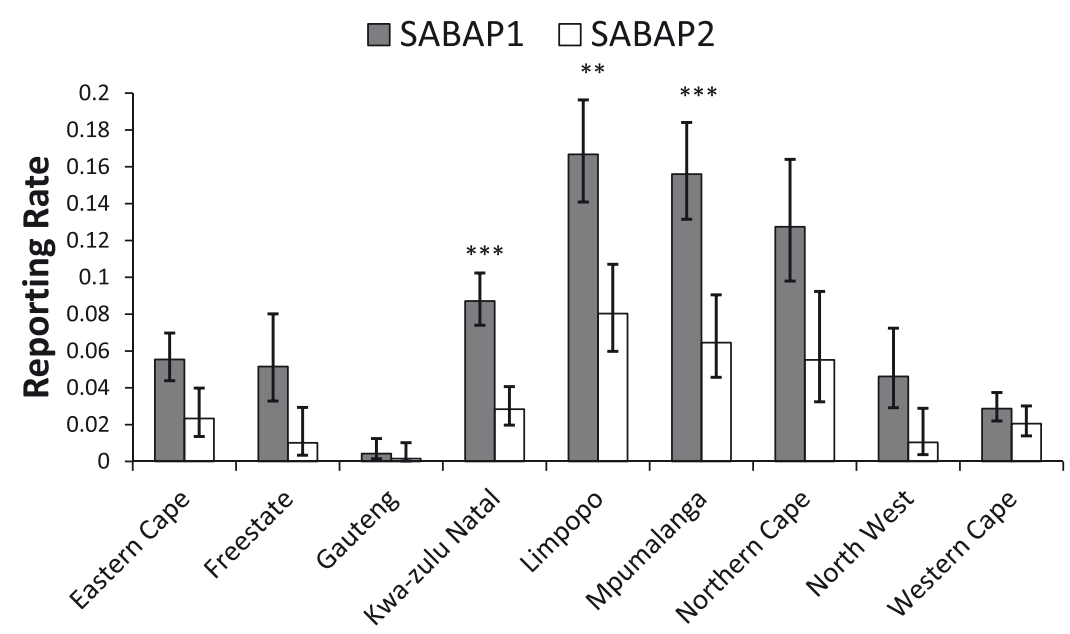

Figure 3. Reporting rates of Martial Eagles across the nine South African provinces between the SABAP projects (mean $\pm 95 \%$ confidence limit). Significant changes are marked as follows: ${ }^{*} P<0.05,{ }^{* *} P<0.01,{ }^{* * *} P<0.001$. 
SABAP1 $\square$ SABAP2

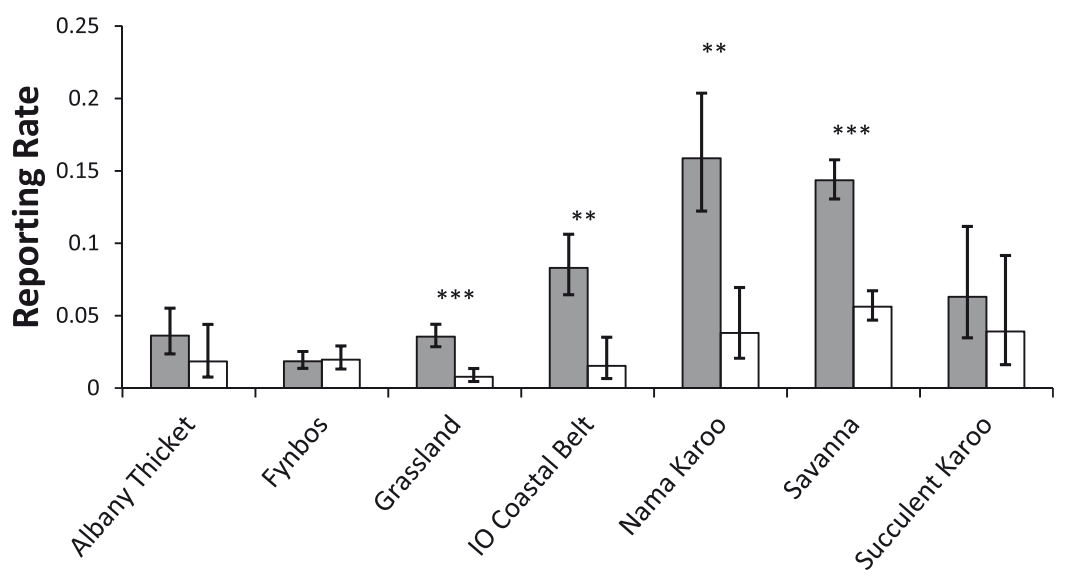

Figure 4. Reporting rates of Martial Eagles across the dominant biomes in South Africa between the SABAP projects (mean $\pm 95 \%$ confidence limit). Significant changes are marked as follows: ${ }^{*} P<0.05,{ }^{* *} P<0.01,{ }^{* * *} P<0.001$. IO=Indian Ocean.

There were significant differences in the changes of reporting rates inside and outside of protected areas (Figure 5), with a significant interaction between PA status and period $\left(\chi^{2}=4 \cdot 3\right.$, $\mathrm{df}=1, P<0.05)$. Pairwise comparison revealed significant decreases in both areas, but with a larger decline of $64 \%$ outside of protected areas $(n=691, t=8.39, P<0.001)$ compared with a $42 \%$ decline inside protected areas $(n=79, t=3.80, P<0.001$ ) (Figure 5$)$.

We also examined changes in reporting rates inside three of South Africa's larger protected areas. Significant declines were apparent for both Kruger and Kalahari Gemsbok National Parks, with a near significant $(P<$ O.I) decline for Hluhluwe-iMfolozi Park. In Kruger National Park, a decline of $54.1 \%$ was recorded dropping from on average reporting rate of $32.2 \%$ $(28.2-36.5 \%)$ per QDGC during SABAP 1 to only $14.8 \%$ (11.5-18.9\%) during SABAP 2. In the Kalahari National Gemsbok Park the reporting rates declined by $44 \%$ with a drop from $32.1 \%(25.7-39.2 \%)$ to $17.9 \%$ (11.6-26.8\%), while for Hluhluwe-iMfolozi a decline of $54.4 \%$ was observed with a drop from $17.8 \%(10.4-28.6 \%)$ to $8.1 \%(3.5-17.4 \%)$ between the two SABAP projects.

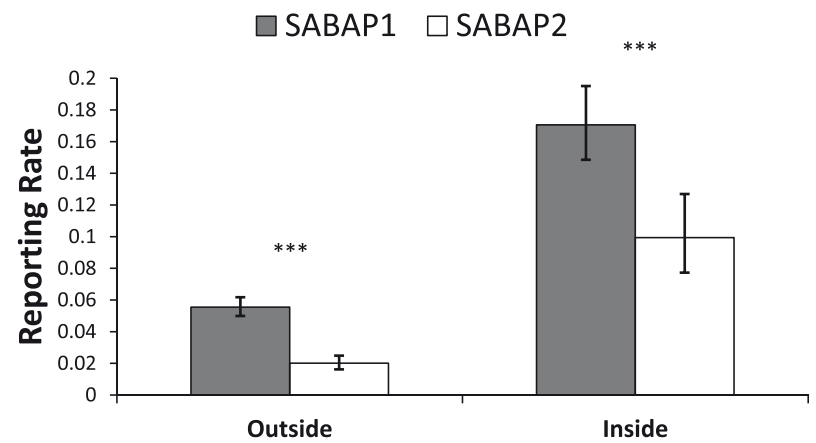

Figure 5. Reporting rates of MEs outside and inside of protected areas in South Africa between the SABAP projects (mean $\pm 95 \%$ confidence limit). Significant changes are marked as follows: ${ }^{*} \mathrm{P}<0.05,{ }^{* *} \mathrm{P}<0.01,{ }^{* * *} \mathrm{P}<0.001$. 


\section{Discussion}

Our analysis revealed large declines in the reporting rates of Martial Eagles across South Africa, with a decline of c.6o\% recorded over the last two decades. Declines were apparent in most provinces and were significant in three provinces (Limpopo, Mpumalanga, KwaZulu-Natal) all of which are located in the east and northeast of the country (Figure 3). The Western Cape was the only province where there appeared to be little change or declines in reporting rates, although the reporting rate in both SABAP surveys was quite low in this region, being only around $2 \%$ (Figure 3 ). Differences were also found between biomes, with declines detected in all biomes, except Albany Thicket, Succulent Karroo and Fynbos biomes. These largely treeless biomes are the dominant habitats in the south-west of the country, mainly in the Western Cape and the west of the Eastern Cape.

Despite the fact that protocols changed between the two SABAP surveys, an analysis by Amar et al. (2016) suggests these changes detected between the comparisons of SABAP surveys were indeed reflective of population changes in this species, a result which has also been found for several other species (Hofmeyr 2012, Shaw 2013). Thus, the declines detected by the analyses in our study are likely to represent real declines in this species, rather than simply reflecting a change in methodology.

Declines in large raptors, including eagle species, have been recorded in other areas of Africa (Thiollay 2006, Virani et al. 2011). However, these surveys have usually relied on repeats of a limited number of road transects and therefore cover a relatively limited area. Road transects across regions in West Africa showed considerable declines in many large eagle species (Thiollay 2006). For Martial Eagles, Thiollay (2006) reported the complete disappearance of Martial Eagles in Burkina Faso, Mali and Niger outside of protected areas, over a 30-year period, and a 50\% decline within protected areas. However, there have been very few comprehensive national analysis of abundance changes for any raptor species in Africa (Krüger et al. 2014), and our study therefore shows the benefit of SABAP for such analyses (Cunningham et al. 2016). The findings from this analysis, together with other information at a more local scale from elsewhere in Africa, have resulted in the Martial Eagle being uplisted to 'Vulnerable' (BirdLife International, 2016).

One of the most important finding from this study is that reporting rates of Martial Eagles declined both inside and outside protected areas. Even within some of our larger protected parks declines were recorded, with significant declines recorded for both the Kalahari (Amar et al. 2016) and Kruger National Park. However, populations within protected areas did appear to be buffered to a degree, with declines being on average $22 \%$ less within protected areas than in non-protected areas. This result suggests that the driving forces for the declines are operating both inside and outside protected areas to some degree. Given the edge effects on wide-ranging species (Woodroffe and Ginsberg 1998) and the fact that this species is highly mobile and can range outside protected areas (e.g. dispersing juveniles), individuals inside protected areas will not be immune to factors operating outside of these areas (Penteriani et al. 2005). Recent research has also indicated that a proportion of seemingly resident adult Martial Eagles may also make long-distance movements outside large protected areas, increasing their exposure to multiple threats that are present outside protected areas (van Eeden et al. 2017).

\section{Potential causes of the decline}

What are the potential factors driving the decline of this species in South Africa? The lack of interaction between province and period, suggests that whatever is driving these declines is potentially happening across the country at a very large scale, rather than resulting from local processes. However, different levels of declines were detected between biomes, with lower levels of decline in the three biomes (Fynbos, Succulent Karoo and Albany Thicket) located within the extreme south-west of the country. Additionally, the lower declines within protected areas may also help identify the causes of the decline. Some of the main threats previously identified for the species include electrocution (van Rooyen and Ledger 1999, Machange et al. 2005) and human persecution (Brown 1991), and these factors may be lower in these areas. 
Recent research on this species within Kruger National Park has identified at least three birds killed by electrocution on powerlines (R. van Eeden unpubl. data), including one of eight GPS tracked birds (van Eeden et al. 2017). However, within the west of the country the species is also known to nest on electric power lines (Boshoff 1993, Machange et al. 2005, Berndt 2015). Indeed, Berndt (2015) estimated the population nesting on the transmission network to be around 150 pairs. The sustainability of the pylon-nesting population remains unknown, in terms of either productivity or survival. For example, it could be that this population represents a sink and suffers from higher mortality rates due to increased collisions or electrocutions (Hernandez-Matias et al. 2013), although the lack of decline detected in the Western Cape (and Fynbos biome) from this study, where a large proportion of the birds nest on pylons, argues against this idea. The density of powerlines is also not noticeably lower within the south-west of the country (Cunningham et al. 2016) where we recorded lower declines of Martial Eagles. Nevertheless, powerlines have been identified as being an important factor in the mortality of large eagles elsewhere (Guil et al. 2011, 2015, Hernández-Matías et al. 2015) and should be investigated further as to whether they are an important driver of the decline in this species.

Other known threats to the species include deliberate killing and inadvertent poisoning (Brown 1991, Anderson 2000). Despite having full legal protection in South Africa, this species is known to be targeted and killed by farmers who blame the species for predation of their livestock, or may be accidentally killed by poison left to kill other predator species (Anderson 20oo). Perhaps the type of farming within the south-west of the country (mainly arable crops and large scale extensive sheep farming) means that the species is less persecuted. Poisoning has been flagged as one of the main drivers of vulture declines, currently occurring throughout Africa (Ogada et al. 2015) and these same drivers are likely to be affecting other large eagles as well. Illegal killing and poisoning have certainly featured prominently in the declines of large raptor in other parts of the world (Margalida 2010, Smart et al. 2010). The species may also be deliberately killed for the use of its body parts in traditional medicine (Msimanga 2016).

\section{Conclusions}

Despite different levels of declines in some biomes and between protected and non-protected areas, the differences between these areas and areas with larger declines are not obvious, and so the likely driving mechanism behind these declines remains unexplained. Future research should focus specifically on identifying the main threats to adult and juvenile survival and on which factors influence breeding productivity. These questions are currently the focus of ongoing research in Kruger National Park (van Eeden et al. 2017) and future research should also extend these questions to other regions, including non-declining regions. Such research would then allow a meaningful Population Viability Analysis to be undertaken to identify the key demographic features driving the decline.

The study shows the value of using SABAP data to quantify changes in abundance of bird species across South Africa. Other studies have explored changes in species abundance in relation to covariates (Cunningham et al. 2016) and such an exercise could be valuable for this and other declining species to identify the potential drivers of change. Future research is urgently required to identify which demographic parameters might be responsible for the population declines described in this study, in order to allow appropriate conservation actions to be implemented to reverse or arrest the decline of this apex predator. Such work is currently being undertaken in Kruger National Park, which is regarded as a stronghold of the South African population (Herholdt and Kemp 1997).

These results contribute to the growing appreciation that many populations of African animal species are declining (Thiollay 2006, Ogada et al. 2015). Unfortunately, unlike many other more developed regions of the world (Magurran et al. 2010), wildlife monitoring programmes at a national scale are rare in African countries. The results from this study show the value of such surveys in an African context and should be encouraged in other African countries to allow further comprehensive monitoring of changes in wildlife populations to be undertaken. 


\section{Acknowledgements}

Thomas Slingsby and Nicholas Lingenberg from the GIS support lab at UCT are thanked for their assistance in processing and preparing the spatial data for this project. Thanks also to Dr Doug Harebottle and his South African Birding Atlas Project colleagues from the Animal Demography Unit, UCT, for providing the core datasets that made this project possible. Thanks to Chrissie Madden and Rowen van Eeden for help and advice.

\section{References}

ADU (Animal Demographic Unit) (2013) The South African Birding Atlas Project 2. Zoology department. University of Cape Town. Available from http://sabapz.adu. org.za/ (Accessed o2 January 2013).

Amar, A., Cloete, D. and Whittington, M. (2016) Using independent nest survey data to validate changes in reporting rates of Martial Eagles between the Southern African Bird Atlas Project 1 and 2. Ostrich 87: 1-5.

Amar, A., Grant, M., Buchanan, G., Sim, I., Wilson, J., Pearce-Higgins, J. W. and Redpath, S. (2011) Exploring the relationships between wader declines and current land-use in the British uplands. Bird Study 58: 13-26.

Anderson, M. D. (2000) Raptor conservation in the Northern Cape province, South Africa. Ostrich 71: 25-32.

Balmford, A., Moore, J. L. and Brooks, T. (2001) Conservation conflicts across Africa. Science 291: 2616-2619.

Bauer, H., Chapron, G., Nowell, K., Henschel, P., Funston, P., Hunter, L. T. B., Macdonald, D. W. and Packer, C. (2015) Lion (Panthera leo) populations are declining rapidly across Africa, except in intensively managed areas. Proc. Natl. Acad. Sci. 112: 14894-14899.

Berndt, J. (2015) Martial Eagles and the national power grid in South Africa: the implications of pylon-nesting for conservation management. MSc thesis, University of Cape Town, South Africa.

BirdLife International (2016) Species factsheet: Polemaetus bellicosus. Available from http://www.BirdLife.org (Accessed 21 July 2016).

BGIS (Biodiversity GIS) (2008) National Protected Area Expansion Strategy 2008. Available from http://bgis.sanbi.org/ protectedAreas/protectedAreas.asp (Accessed 30 September 2012).
Bled, F., Nichols, J. D. and Altwegg, R. (2013) Dynamic occupancy models for analyzing species' range dynamics across large geographic scales. Ecol. Evol. 3: 4896-4909.

Bonnevie, B. T. (2011) Some considerations when comparing SABAP $I$ with SABAP 2 data. Ostrich 82: 161-162.

Boshoff, A. F. (1993) Density, breeding performance and stability of Martial Eagles Polemaetus bellicosus breeding on electricity pylons in the Nama Karoo, South Africa. Annalen-Koninklijk Museum voor MiddenAfrika. Zoologische Wetenschappen 268: 95-104.

Brashares, J. S. and Sam, M. K. (2005) How much is enough? Estimating the minimum sampling required for effective monitoring of African reserves. Biodivers. Conserv. 14: 2709-2722.

Brown, C. J. (1991) Declining Martial Polemaetus bellicosus and Tawny Aquila rapax Eagle populations and causes of mortality on farmlands in central Namibia. Biol. Conserv. 56: 49-62.

Buckland, S. T., Magurran, A. E., Green, R. E. and Fewster, R. M. (2005) Monitoring change in biodiversity through composite indices. Philos. Trans. R. Soc. Lond. B. Biol. Sci. 360 : 243-254.

Cunningham, S. J., Madden, C. F., Barnard, P. and Amar, A. (2016) Electric crows: powerlines, climate change and the emergence of a native invader. Divers. Distrib. 22: 17-29.

ESRI (2011) ArcGIS Desktop: Release 9.3. Redlands, CA: Environmental Systems Research Institute.

Guil, F., Fernández-Olalla, M., Moreno-Opo, R., Mosqueda, I., García, M. E., Aranda, A., Arredondo, A., Guzmán, J., Oria, J., Margalida, A. and González, L. M. (2011) Minimising mortality in endangered 
raptors due topowerlines:theimportance of spatial aggregation to optimize application of mitigation measures. PLoS One 6: e28212.

Guil, F., Colomer, M. A., Moreno-Opo and Margalida, A. (2015) Space-time trends in Spanish bird electrocution rates from alternative information sources. Global Ecol. Conserv. 3: 379-388.

Harrison, J. A. and Underhill, L. G. (1997) Introduction and methods. Pp xliii-lxiv in J. A. Harrison, D. G. Allan, L. G. Underhill, M. Herremans, A. J. Tree, V. Parker and C. J. Brown, eds. The atlas of southern African birds. Volume 1: Non-passerines. Johannesburg, South Africa: BirdLife South Africa.

Haub, C. and Kent, M. (1989) World population data sheet. Washington DC: Population Reference Bureau Inc.

Henschel, P., Coad, L., Burton, C., Chataigner, B., Dunn, A., MacDonald, D., Saidu, Y. and Hunter, L. T. B. (2014) The lion in West Africa is critically endangered. PLoS One 9: e8350o.

Herholdt, J. and Kemp, A. (1997) Breeding status and ecology of the Martial Eagle in the Kalahari Gemsbok National Park, South Africa. Ostrich 68: 80-85.

Hernández-Matías, A., Real, J., Moleón, M., Palma, L., Sánchez-Zapata, J. A., Pradel, R., Carrete, M., Gil-Sánchez, J. M., Beja, P., Balbontín, J., Vincent-Martin, N., Ravayrol, A., Benítez, J. R., Arroyo, B., Fernández, C., Ferreiro, E. and García, J. (2013) From local monitoring to a broad-scale viability assessment: a case study for the Bonelli's Eagle in western Europe. Ecol. Monogr. 83: 239-261.

Herremans, M. and Herremans-tonnoeyr, D. (2000) Land use and the conservation status of raptors in Botswana. Biol. Conserv. 94: 31-41.

Hewson, C., Amar, A., Lindsell, J., Thewlis, R., Butler, S., Smith, K. and Fuller, R. (2007) Recent changes in bird populations in British broadleaved woodland. Ibis (Lond. 1859) 149: 14-28.

Hofmeyr, S. D. (2012) Impacts of environmental change on large terrestrial bird species in South Africa : insights from citizen science data. PhD thesis. University of Cape Town, South Africa.

Krüger, S. C., Allan, D. G., Jenkins, A. R. and Amar, A. (2014) Trends in territory occupancy, distribution and density of the Bearded Vulture Gypaetus barbatus meridionalis in southern Africa. Bird Conserv. Internatn. 24: 162-177.

Lenth, R. V. and Hervé, M. (2013) lsmeans: Leastsquares means. R package version 2.11. available at http://CRAN.R-project.org/package= lsmeans (accessed on 4th April 2013).

Lindsell, J. A., Klop, E. and Siaka, A. M. (2016) The impact of civil war on forest wildlife in West Africa: mammals in Gola Forest, Sierra Leone. Oryx 45: 69-77.

Machange, R. W., Jenkins, A. R. and Navarro, R. A. (2005) Eagles as indicators of ecosystem health: Is the distribution of Martial Eagle nests in the Karoo, South Africa, influenced by variations in land-use and rangeland quality? J. Arid Environ. 63: 223-243.

Magurran, A. E., Baillie, S. R., Buckland, S. T., Dick, J. M., Elston, D. A, Scott, E. M., Smith, R. I., Somerfield, P. J. and Watt, A. D. (2010) Long-term datasets in biodiversity research and monitoring: assessing change in ecological communities through time. Trends Ecol. Evol. 25: 574-582.

Margalida, A. (2010) Baits, budget cuts: a deadly mix. Science 338: 192.

MDB (Municipal Demarcation Board) (2013) Provincial boundary data for South Africa. Available from http://www.demarcation. org.za (Accessed o4 April 2013).

Msimanga, A. (2016) The role of birds in the culture of the Ndebele people of Zimbabwe. Ostrich 71: 22-24.

Mucina, L. and Rutherford, M. C. (2006) The vegetation of South Africa, Lesotho and Swaziland. Pretoria, South Africa: National Biodiversity Institute.

Murgatroyd, M., Underhill, L. G., Rodrigues, L. and Amar, A. (2016) The influence of agricultural transformation on the breeding performance of a top predator: Verreaux's Eagles in contrasting land use areas. Condor 118: $238-252$

Odhiambo, N. M. (2009) Electricity consumption and economic growth in South Africa : A trivariate causality test. Energy Econ. 31: 635-640.

Ogada, D., Shaw, P., Beyers, R. L., Buij, R., Murn, C., Thiollay, J. M., Beale, C. M., Holdo, R. M., Pomeroy, D., Baker, N., Krüger, S. C., Botha, A., Virani, M. Z., 
Monadjem, A. and Sinclair, A. R. E. (2015) Another continental vulture crisis: Africa's vultures collapsing toward extinction. Conserv. Lett. 9: 89-97.

Ortega, E., Manosa, S., Margalida, A., Sanchez, R., Oria, J. and Gonzalez, L. M. (2009) A demographic description of the recovery of the Vulnerable Spanish imperial eagle Aquila adalberti. Oryx 43: 113-121.

Penteriani, V., Otalora, F., Sergio, F. and Ferrer, M. (2005) Environmental stochasticity in dispersal areas can explain the "mysterious" disappearance of breeding populations. Proc. Biol. Sci. 272: 1265-1269.

$\mathrm{R}$ Core Team (2015) R: A language and environment for statistical computing. Vienna, Austria: R Foundation for Statistical Computing.

SANBI (South African National Biodiversity Institute) (2012) National Biodiversity Assessment 2011. Terrestrial Formal Protected Areas (vector geospatial dataset) 2012. Available at http://bgis.sanbi. org/SpatialDataset/Detail/412. (Accessed 30 September 2012).

Sergio, F., Newton, I., Marchesi, L. and Pedrini, P. (2006) Ecologically justified charisma: preservation of top predators delivers biodiversity conservation. J. Appl. Ecol. 43: 1049-1055.

Shaw, J. M. (2013) Power line collisions in the Karoo: Conserving Ludwig's Bustard. PhD thesis. University of Cape Town, South Africa.

Smart, J., Amar, A., Sim, I. M. W., Etheridge, B., Cameron, D., Christie, G. and Wilson, J. D. (2010) Illegal killing slows population recovery of a re-introduced raptor of high conservation concern - the red kite Milvus milvus. Biol. Conserv. 143: 1278-1286.

Taylor, M. R., Peacock, F. and Wanless, R. W. (2015) The Eskom Red Data Book of birds of South Africa, Lesotho and Swaziland. Johannesburg, South Africa: BirdLife South Africa.

Thiollay, J. (2006) The decline of raptors in West Africa : long-term assessment and the role of protected areas. Ibis (Lond. 1859) 148: 240-254.

Underhill, L. (2012) Martial Eagle spirals downwards. SABAP news. Anim. Demogr. Unit, Univ. Cape Town. Available at http://www.adu.org.za/news.php?id=238 (Accessed 02 January 2013).

van Eeden, R., Whitfield, D. P., Botha, A. and Amar, A. (2017) Ranging behaviour and habitat preferences of the Martial Eagle: Implications for the conservation of a declining apex predator. PLoS One 12: e0173956.

Virani, M. Z., Kendall, C., Njoroge, P. and Thomsett, S. (2011) Major declines in the abundance of vultures and other scavenging raptors in and around the Masai Mara ecosystem, Kenya. Biol. Conserv. 144: 746-752.

van Rooyen, C. S. and Ledger, J. A. (1999) Birds and utility structures: developments in southern Africa. Pp. 205-230 in M. Ferrer and G. F. M. Janns, eds. Birds and power lines. Madrid, Spain: Quercus.

Western, D., Russell, S. and Cuthil, I. (2009) The status of wildlife in protected areas compared to non-protected areas of Kenya. PLoS One 4(7): e6140.

Woodroffe, R. and Ginsberg, J. (1998) Edge effects and the extinction of populations inside protected areas. Science 280 : 2126-2128.

\section{ARJUN AMAR*, DANIËL CLOETE \\ FitzPatrick Institute of African Ornithology, DST-NRF Centre of Excellence, University of Cape Town, Cape Town, South Africa.}

*Author for correspondence; e-mail:arjun.amar@uct.ac.za

Received I December 2016; revision accepted 21 July 2017; Published online 14 September 2017 